\title{
Development of thermostable sucrose phosphorylase by semi-rational design for efficient biosynthesis of alpha-D-glucosylglycerol
}

\author{
Yuanyuan Xia ${ }^{1,2} \cdot{\text { Xiaoyu } \mathrm{Li}^{1,2} \cdot \text { Linli Yang }^{1,2} \cdot \text { Xiaozhou Luo }^{1,3} \cdot \text { Wei Shen }}^{1,2} \cdot$ Yu Cao $^{1,2} \cdot$ Lukasz Peplowski $^{4}(\mathbb{0}$. \\ Xianzhong Chen ${ }^{1,2}$ (1)
}

Received: 17 April 2021 / Revised: 3 August 2021 / Accepted: 24 August 2021 / Published online: 20 September 2021

(c) The Author(s) 2021

\begin{abstract}
Sucrose phosphorylase (SPase) can specifically catalyze transglycosylation reactions and can be used to enzymatically synthesize $\alpha$-D-glycosides. However, the low thermostability of SPase has been a bottleneck for its industrial application. In this study, a SPase gene from Leuconostoc mesenteroides ATCC 12,291 (LmSPase) was synthesized with optimized codons and overexpressed successfully in Escherichia coli. A semi-rational design strategy that combined the FireProt (a web server designing thermostable proteins), structure-function analysis, and molecular dynamic simulations was used to improve the thermostability of $L m$ SPase. Finally, one single-point mutation T219L and a combination mutation I31F/T219L/T263L/ S360A (Mut4) with improved thermostability were obtained. The half-lives at $50{ }^{\circ} \mathrm{C}$ of $\mathrm{T} 219 \mathrm{~L}$ and Mut 4 both increased approximately two-fold compared to that of wild-type $\operatorname{LmSPase}(\mathrm{WT})$. Furthermore, the two variants T219L and Mut4 were used to produce $\alpha$-D-glucosylglycerol $(\alpha \mathrm{GG})$ from sucrose and glycerol by incubating with $40 \mathrm{U} / \mathrm{mL}$ crude extracts at $37{ }^{\circ} \mathrm{C}$ for $60 \mathrm{~h}$ and achieved the product concentration of $193.2 \pm 12.9 \mathrm{~g} / \mathrm{L}$ and $195.8 \pm 13.1 \mathrm{~g} / \mathrm{L}$, respectively, which were approximately 1.3 -fold higher than that of WT $(150.4 \pm 10.0 \mathrm{~g} / \mathrm{L})$. This study provides an effective strategy for improving the thermostability of an industrial enzyme.
\end{abstract}

Key points

- Predicted potential hotspot residues directing the thermostability of LmSPase by semi-rational design

- Screened two positive variants with higher thermostability and higher activity

- Synthesized $\alpha$-D-glucosylglycerol to a high level by two screened positive variants

Keywords Sucrose phosphorylase $\cdot$ Thermostability $\cdot$ Semi-rational design $\cdot \alpha$-D-glucosylglycerol $\cdot$ Molecular dynamics simulations

Lukasz Peplowski

drpepe@ fizyka.umk.pl

$\triangle$ Xianzhong Chen

xzchen@jiangnan.edu.cn

1 Key Laboratory of Industrial Biotechnology, Ministry of Education, School of Biotechnology, Jiangnan University, 1800 Lihu Avenue, Wuxi 214122, Jiangsu, China

2 School of Biotechnology, Jiangnan University, Wuxi 214122, Jiangsu, China

3 Center for Synthetic Biochemistry, Shenzhen Institutes of Advanced Technology, Chinese Academy of Sciences, Shenzhen 518055, China

4 Institute of Physics, Faculty of Physics, Astronomy and Informatics, Nicolaus Copernicus University in Torun, Grudziadzka 5, 87-100 Torun, Poland

\section{Introduction}

Sucrose phosphorylase (SPase, EC 2.4.1.7) can catalyze the phosphorolysis of sucrose into $\alpha$-D-glucose 1-phosphate $(\alpha-\mathrm{D}-\mathrm{G} 1 \mathrm{P})$ and D-fructose, and it can glycosylate a broad range of acceptors other than phosphate (Goedl et al. 2010). SPase has outstanding potential for biocatalytic conversion of ordinary table sugar into products with attractive properties (Franceus and Desmet 2020), and it is widely used in the fields of food, medicine, and cosmetics (O'Neill and Field 2015). For instance, SPase can be used to synthesize fine chemicals such as $\alpha$-D-glucosylglycerol ( $\alpha \mathrm{GG})$, which is synthesized from one molecule of sucrose and one glycerol. The $\alpha G G$ has a beneficial function as a humectant in cosmetics and has potential as a healthy food material and therapeutic agent (Bolivar et al. 2017). 
Industrial carbohydrate conversion is preferably performed at a higher temperature to avoid microbial contamination (Haki and Rakshit 2003). During the production process, SPase with a high thermostability would reduce the production time under high temperatures and remain active after prolonged continuous catalysis. SPase from L. mesenteroides ATCC 12,291 ( $L m$ SPase) was reported to have high activity to synthesize $\alpha$-arbutin but poor thermostability, restricting its industrial applications (Yao et al. 2020). In the process of synthesizing $\alpha \mathrm{GG}$, due to the long reaction time, it is usually necessary to keep the temperature at $30{ }^{\circ} \mathrm{C}$ (Bolivar et al. 2017; Goedl et al. 2008). Therefore, improving the thermostability of enzymes to enhance their usability in the industry has attracted increasing interest, and thus, various auxiliary methods have been developed to help predict potential thermostable mutants (Sun et al. 2019; Xu et al. 2020). The semi-rational design combines the benefits of directed evolution and rational design and is suitable for modifying proteins without high-throughput determination methods and structure-function understanding (Chica et al. 2005). Many successful examples have reported that changing a few amino acids can significantly improve the protein thermostability by semi-rational design strategies (Cheng et al. 2020; Roth et al. 2017).

In this study, a semi-rational design strategy that combined the FireProt, a web server designed to predict thermostable mutants concerning structural and evolutionary information automatedly, structure-function analysis, and molecular dynamics (MD) simulations were used to improve the thermostability of $L m$ SPase. Several residues which potentially affect the thermostability of $L m$ SPase were selected, and site-directed mutagenesis was performed on the corresponding residues. To test whether the selected mutants can have advantages in industrial applications, we carried out the catalytic synthesis of $\alpha \mathrm{GG}$ at a relatively high temperature.

\section{Materials and methods}

\section{Plasmid construction}

The SPase gene from L. mesenteroides ATCC 12,291 (LmSPase) synthesized with the optimized codon (BankIt2453263 Seq2453263 MZ005078) was inserted between the NcoI and XhoI restriction enzyme sites of the pET28a plasmid. The recombinant plasmid pET28aLmSPase was expressed in Escherichia coli BL21(DE3). The site-directed mutation was constructed using the QuikChange method with pET28a-LmSPase as the template, and the primers are listed in Table S1. Then, the PCR products were purified and digested by endonuclease $D p n \mathrm{I}$ to remove the template plasmid containing the methylation modification. The PCR product was then transformed into competent $E$. coli BL21(DE3) cells with the chemical transformation method. The transformants grown on the plate were picked for sequencing, and the recombinant bacteria with the correct sequence were selected. The recombinant E. coli was first cultivated in liquid Luria-Bertani (LB) broth at $37{ }^{\circ} \mathrm{C}$ overnight. Then, $0.5 \mathrm{~mL}$ of the cultured bacteria were transferred to $50 \mathrm{~mL}$ of terminal broth (TB) medium containing $50 \mu \mathrm{g} / \mathrm{mL}$ kanamycin and grown at $37{ }^{\circ} \mathrm{C}$ with shaking at $200 \mathrm{rpm}$. When the culture reached an optical density at $600 \mathrm{~nm}$ (OD600) of 0.6, $0.5 \mathrm{mM}$ isopropyl $\beta$-D1-thiogalactoside (IPTG) was added to induce $L m$ SPase expression and cultured at $25{ }^{\circ} \mathrm{C}$ for $24 \mathrm{~h}$. The bacteria were collected by centrifugation and ultrasonically lysed to obtain a soluble supernatant. The protein concentration was adjusted to be consistent between samples, and the protein was verified by SDS-PAGE.

\section{Homology modeling and mutant library construction}

For the hotspot residues prediction, the three-dimensional (3D) structure of $L m$ SPase is used as input for FireProt (https://loschmidt.chemi.muni.cz/fireprot/) was obtained through the online prediction website called Iterative Threading ASSEmbly Refinement (I-TASSER, https:// zhanglab.ccmb.med.umich.edu/I-TASSER/) (Roy et al. 2010; Yang et al. 2015; Zhang 2008). Then, a new, highquality homology model was obtained by SWISS-MODEL (Guex et al. 2009; Waterhouse et al. 2018) as a new crystal structure with higher sequence similarity was released after we finished identifying predicted mutants. The LmSPase model obtained by I-TASSER was evaluated with the structure scoring programs SAVES and PROCHECK. The model with higher scores was used as the input file for further analyses. The mutant library was constructed with an in-silico design program FireProt based on the predicted change in Gibbs free energy $(\Delta \Delta G)$ upon mutation. FireProt employed the dataset derived from the ProTherm database to identify the stable single-point mutations either by energy- or evolution-based approaches. After submitting the model PDB file to the FireProt online program, two mutation lists were generated after the evolution- and energy-based calculation approaches, and a third list combined the above two methods. We selected candidate mutants from the first two lists based on the $\Delta \Delta \mathrm{G}$ values.

\section{Purification of LmSPase and its variants}

All protein purification steps were performed at $0-4{ }^{\circ} \mathrm{C}$. The harvested cell pellet containing His-tagged enzyme was resuspended in a binding buffer $(20 \mathrm{mM}$ sodium phosphate, $0.5 \mathrm{M} \mathrm{NaCl}$, and $5 \mathrm{mM}$ imidazole ( $\mathrm{pH} 7.4)$ ) and 
lysed by ultrasonication. The supernatants were obtained by centrifugation at $13,000 \times g$ for $45 \mathrm{~min}$. The supernatants were filtered through a $0.22-\mu \mathrm{m}$ pore-size filter. The Histagged protein was loaded onto a His-Trap affinity chromatography using AKTA Avant (GE Healthcare UK Ltd) and eluted by elution buffer (binding buffer with $0.5 \mathrm{M}$ imidazole). Fractions containing target proteins were analyzed by SDS-PAGE. The purified wild-type LmSPase was loaded onto a Superdex ${ }^{\text {TM }} 200$ 10/300 GL column (GE Healthcare, Mickleton, NJ), and the molecular weight was determined and calculated from the standard curve of marker proteins (Oriental Yeast Co., Ltd.).

\section{Activity assays of LmSPase and its variants}

LmSPase catalyzes the reversible phosphorolysis of sucrose to produce $\alpha$-D-G1P and D-fructose, and the enzyme activity can be measured by determining the fructose produced. LmSPase was assayed in a 1-mL-reaction mixture containing $500 \mu \mathrm{L}$ of $5 \%$ sucrose, $450 \mu \mathrm{L}$ of $50 \mathrm{mM}$ sodium phosphate buffer (pH 6.5), and $50 \mu \mathrm{L}$ of $L m S$ Pase crude extract or pure enzyme solution $(0.01 \mathrm{mg} / \mathrm{mL})$. The mixture was incubated at $30{ }^{\circ} \mathrm{C}$ for $10 \mathrm{~min}$ and terminated by adding $1.5 \mathrm{~mL}$ of 3,5-dinitrosalicylic acid (DNS) and heating in boiling water for $15 \mathrm{~min}$ and detected at $540 \mathrm{~nm}$ using UV-Vis spectrophotometer. The fructose concentration in the reaction mixture was determined by a fructose standard curve using the same DNS method. The amount of enzyme required to hydrolyze sucrose to release $1 \mu \mathrm{mol}$ of fructose per minute is defined as one activity unit (U).

\section{Thermostability assays of LmSPase and its variants}

The thermostability of crude $L m$ SPase and its variants was assayed by incubating $0.01 \mathrm{mg} / \mathrm{mL}$ crude enzyme extract at $50{ }^{\circ} \mathrm{C}$ for $10 \mathrm{~min}$, and the residual activity was tested. The activity of $L m S P$ ase without heat treatment was taken as $100 \%$.

The half-lives $\left(t_{1 / 2}\right)$ of $L m S P a s e$ and variants were evaluated by incubating $0.01 \mathrm{mg} / \mathrm{mL}$ purified enzymes for $90 \mathrm{~min}$ in a water bath at $50{ }^{\circ} \mathrm{C}$ and testing their residual activity every $10 \mathrm{~min}$. The half-life of each enzyme was calculated by fitting the data points with exponential decay curves.

The melting temperature $\left(T_{\mathrm{m}}\right)$ of a protein can be used to describe its thermodynamic stability, and $T_{\mathrm{m}}$ was determined by nano-differential scanning calorimetry (nano-DSC, TA Instruments, New Castle, DE), which can capture the heat capacity change in the protein during heating. The concentration of $L m$ SPase and its variants was adjusted to $0.5 \mathrm{mg} /$ $\mathrm{mL}$, and the instrument scanned from 20 to $100{ }^{\circ} \mathrm{C}$ by the scan rate at $1{ }^{\circ} \mathrm{C} / \mathrm{min}$. The heat capacity curve of the sample was analyzed with nano-DSC analysis software by fitting a curve after subtracting the blank control.

\section{CD measurements of LmSPase and its variants}

Circular dichroism (CD) spectroscopy is an acknowledged technique for analyzing the secondary structure of soluble proteins. The CD spectrum of $L m S$ Pase and its variants was measured on the MOS-450/AF-CD-STP-A instrument (BioLogic, Grenoble, France) from 195 to $250 \mathrm{~nm}$. Each purified enzyme solution was diluted in $50 \mathrm{mM}$ sodium phosphate buffer ( $\mathrm{pH} 6.5$ ) at a protein concentration of $0.2 \mathrm{mg} / \mathrm{mL}$.

\section{Synthesis of aGG by LmSPase}

Recombinant $L m$ SPase was used to transfer a glucose group of sucrose to the acceptor glycerol to produce $\alpha \mathrm{GG}$. The $\alpha$ GG reaction mixture containing $1.2 \mathrm{~mol} / \mathrm{L}$ sucrose, $2 \mathrm{~mol} / \mathrm{L}$ glycerol, and $40 \mathrm{U} / \mathrm{mL}$ crude extract of $\mathrm{LmSPase}$ was incubated at $37^{\circ} \mathrm{C}$ in 2-(N-morpholino) ethanesulfonic acid (MES) buffer at $\mathrm{pH}$ 6.5. The $\alpha \mathrm{GG}$ was analyzed by high-performance liquid chromatography (HPLC) with a refractive index detector (RID) using a Waters XBridge Amide $(4.6 \mathrm{~mm} \times 250 \mathrm{~mm}, 5 \mu \mathrm{m})$ column. The mobile phase was composed of $85 \%$ acetonitrile and $15 \% 1 \%$ ammonia. The concentration of $\alpha \mathrm{GG}$ was calculated from the standard curve by extrapolation.

\section{MD simulations}

As an input structure for the MD analysis, the homology model obtained by SWISS-MODEL (Guex et al. 2009; Waterhouse et al. 2018) based on the 6S9V (Franceus et al. 2019) PDB template was used. Amino acid protonation states were determined using the PROPKA3 tool (Olsson et al. 2011) encoded on the PDB2PQR server (Dolinsky et al. 2007, 2004). Mutations were generated using the mutate option in the psfgen tool-part of the NAMD code (Phillips et al. 2005). The water box was generated with $0.15 \mathrm{~mol} / \mathrm{L} \mathrm{Na}^{+}$and $\mathrm{Cl}^{-}$. The final simulation system was $91 \times 75 \times 77 \AA$.

In each system, the water box was equilibrated during a 1-ns simulation at $300 \mathrm{~K}$, and then 1000 minimization steps for the whole system were performed. Next, for each case, a 100-ns simulation at $300 \mathrm{~K}$ with periodic boundary conditions, long-range electrostatics calculated with Ewald summation, and atmospheric pressure calculated using the Langevin algorithm were obtained. The time step was set to $1 \mathrm{fs}$. As input homology structure models were used, the first $50 \mathrm{~ns}$ of the simulation were treated as an equilibration stage. All details for these simulations at $335 \mathrm{~K}$ were the same as those for simulations at $300 \mathrm{~K}$, except for the temperature. To heat the temperature from 300 to $335 \mathrm{~K}$, stepwise heating for $45 \mathrm{ps}$ of the simulation was performed.

All MD simulations were calculated using NAMD 2.12 code (Phillips et al. 2005, 2020) with the Charmm27 
forcefield (Mackerell et al. 2004; MacKerell et al. 1998). In addition, analysis of 50-100 ns parts of simulations at $300 \mathrm{~K}$ and $335 \mathrm{~K}$ was performed using VMD (Humphrey et al. 1996) code and homemade scripts.

\section{Results}

\section{Production of recombinant His-tagged LmSPase}

The SPase gene of L. mesenteroides ATCC 12,291 was cloned into the pET28a vector after codon optimization and successfully overexpressed in E. coli BL21(DE3) (Figure $\mathrm{S} 1 \mathrm{~A})$. The $\mathrm{LmSPase}$ protein carries a His-tag at the N-terminus with a theoretical molecular mass of $56.8 \mathrm{kDa}$, and the apparent molecular weight of $L m S P a s e$ is $63.4 \mathrm{kDa}$, as determined by size-exclusion chromatography (Figure S1B), which confirmed that $L m$ SPase exists as a monomer, and the purified SPase proteins were used to test their characteristics.

\section{Homology modeling of LmSPase}

The sucrose phosphorylase (PDB ID: 2GDV) was selected as a template because it shared the highest amino acid sequence identity with $L m$ SPase at the beginning of the research. Then, the model served as an input structure for the FireProt server to generate a mutation pool (Musil et al. 2017). Subsequently, to explore the reasons for increased thermostability, a new model was built for MD simulations because a new crystal structure with higher sequence similarity was released in August 2019, which was after we obtained the positive mutants. The crystal structure of sucrose $6 \mathrm{~F}$-phosphate phosphorylase from Thermoanaerobacter thermosaccharolyticum (Franceus et al. 2019) (PDB ID: 6S9V) has the highest amino acid identity (40\%). The homological models were validated by the VERIFY3D server (Eisenberg et al. 1997; Luthy et al. 1992). The SWISS-MODEL and I-TASSER homology models had $99.17 \%$ and $82.86 \%$ of the amino acids, respectively, with an average 3D-1D score larger than 0.2 , and the structure should have at least $80 \%$ of the amino acids with an average 3D-1D score larger than 0.2 to pass verification (Eisenberg et al. 1997; Luthy et al. 1992).

\section{Hotspot residues prediction}

FireProt is a web server designed to predict thermostable mutants concerning structural and evolutionary information automatedly. The FoldX (Schymkowitz et al. 2005) and Rosetta (Alford et al. 2017) tools in the server were used to compute the energy from the input structure based on authentic experimentally validated databases and simulations of the atoms' force fields separately. FireProt also excluded strictly conserved residues that might negatively affect structural folding. Thus, FireProt was selected to generate a pool of $L m S$ Pase variants that may be more stable than the WT. After calculation, a list containing 33 energy mutants and 31 evolution mutants was generated. Then, MD simulations and structural analyses of the WT were carried out. Among the mutants listed, Rosetta-based mutations with less than $-2 \mathrm{kcal} / \mathrm{mol}$ folding free energy $(\Delta \Delta \mathrm{G})$ and FoldX-based mutations with less than $-1 \mathrm{kcal} / \mathrm{mol} \Delta \Delta \mathrm{G}$ were selected (Bednar et al. 2015) (Table 1). In addition,

Table 1 Characteristics of predicted LmSPase mutants

\begin{tabular}{|c|c|c|c|c|c|}
\hline & Enzyme & $\begin{array}{l}\text { Activity before heat- } \\
\text { ing }(\%)^{[\mathrm{a}]}\end{array}$ & $\begin{array}{l}\text { Activity after heat- } \\
\text { ing }(\%)\end{array}$ & $\begin{array}{l}\text { Rosetta } \\
\Delta \Delta \mathrm{G}\left(\mathrm{kcal} \bullet \mathrm{mol}^{-1}\right)\end{array}$ & $\begin{array}{l}\text { FoldX } \\
\Delta \Delta \mathrm{G}\left({\left.\mathrm{kcal} \bullet \mathrm{mol}^{-1}\right)}^{-1}\right.\end{array}$ \\
\hline \multirow{3}{*}{ Energy-based mutants } & WT & $100.0 \pm 1.4$ & $33.0 \pm 4.6$ & $-^{[\mathrm{b}]}$ & - \\
\hline & $\mathrm{I} 31 \mathrm{~F}$ & $104.0 \pm 2.5$ & $40.4 \pm 1.7$ & -12.03 & -3.21 \\
\hline & $\mathrm{T} 152 \mathrm{G}$ & $128.2 \pm 7.6$ & N.D..$^{[c]}$ & -41.15 & -1.31 \\
\hline \multirow{9}{*}{ Evolution-based mutants } & A232M & $56.4 \pm 3.8$ & N.D & -37.79 & -1.54 \\
\hline & G252L & $79.6 \pm 1.5$ & N.D & -2.49 & -13.48 \\
\hline & Q453G & $147.3 \pm 2.4$ & $46.5 \pm 0.2$ & -13.47 & -4.34 \\
\hline & $\mathrm{N} 158 \mathrm{C}$ & $69.0 \pm 5.1$ & $37.5 \pm 1.6$ & - & -2.77 \\
\hline & $\mathrm{T} 219 \mathrm{~L}$ & $142.2 \pm 4.1$ & $118.8 \pm 2.4$ & - & -1.50 \\
\hline & $\mathrm{N} 249 \mathrm{~A}$ & $101.9 \pm 0.3$ & $20.4 \pm 0.4$ & - & -1.08 \\
\hline & $\mathrm{T} 263 \mathrm{~L}$ & $95.1 \pm 9.7$ & $51.0 \pm 3.9$ & - & -1.04 \\
\hline & S360A & $108.4 \pm 3.5$ & $53.7 \pm 0.8$ & - & -1.44 \\
\hline & Mut4 & $97.1 \pm 3.9$ & $84.0 \pm 8.2$ & - & - \\
\hline
\end{tabular}

${ }^{[\mathrm{a}]}$ The enzyme activity is measured by determining the fructose produced, and the $1-\mathrm{mL}$ reaction mixture contains $500 \mu \mathrm{L}$ of $5 \%$ sucrose, $450 \mu \mathrm{L}$ of $50 \mathrm{mM}$ sodium phosphate buffer (pH 6.5), and $50 \mu \mathrm{L}$ of crude extracts. The activity of crude WT before heated was taken as $100 \%$, and other crude enzymes' relative activity before or after heated at $50{ }^{\circ} \mathrm{C}$ for $10 \mathrm{~min}$ was calculated based on WT

${ }^{[b]}$ Not applicable

${ }^{[c]}$ Not detectable 
after MD simulations, the mutation with a root-mean-square fluctuation (RMSF) lower than the average value of $2.12 \AA$ at $300 \mathrm{~K}$ was eliminated (Fig. 1). Additionally, if the $\alpha$ carbon atom of the residue predicted by FireProt had a distance to the active site of $L m$ SPase less than $10 \AA$, this residue was removed from the mutant list. Finally, ten mutations were selected (Fig. 1).

\section{Characterization of the ten selected mutants}

Ten variants were constructed and expressed in E. coli BL21(DE3), and the harvested bacteria were analyzed by SDS-PAGE (Figure S2). Compared with the negative control, these variants all had an obvious band at approximately $55 \mathrm{kDa}$, indicating that all the variants were expressed successfully. To determine the thermostability of the variants, we incubated the crude enzyme supernatants of WT and mutant enzymes at $50{ }^{\circ} \mathrm{C}$ for $10 \mathrm{~min}$ and tested the phosphorolysis of sucrose to produce $\alpha-\mathrm{D}-\mathrm{G} 1 \mathrm{P}$ and fructose (Table 1). Then, the activity of the enzyme without heat treatment and the residual activity after heat treatment were determined under optimal reaction conditions. The results showed that the crude enzymes of I31F, N158C, T219L, S360A, and T263L had better thermostability than WT (Table 1). However, the activity of N158C without heat treatment decreased to $69 \%$ of that of the WT. Therefore, a combination mutation containing the four positive mutations (I31F/T219L/T263L/S360A, Mut4) was constructed and analyzed. After incubation at $50{ }^{\circ} \mathrm{C}$ for $10 \mathrm{~min}$, Mut4 retained more than $50 \%$ residual activity with partial loss of its specific activity. Finally, five positive variants, I31F, T219L, S360A, T263L, and Mut4, were selected to study further.

\section{Characterization of the thermostable variants}

To further characterize the enzymes in detail, the WT and five positive variants were purified by affinity chromatography and size-exclusion chromatography, and the pure protein bands were shown in the even-numbered lanes of SDS-PAGE (Fig. 2A). To determine the thermostability of the WT LmSPase and its variants, the purified enzyme solutions were adjusted to the same concentration and incubated at $50{ }^{\circ} \mathrm{C}$, and their relative residual enzymatic activities were measured every $10 \mathrm{~min}$. Compared with the half-life of WT, the variants T219L and Mut4 exhibited longer half-life (Fig. 2B). The half-life of T219L and Mut4 was calculated as $48.7 \mathrm{~min}$ and $53.1 \mathrm{~min}$, respectively, which increased by 2.3-fold and 2.6-fold compared with that of WT, respectively (Table 2). However, the half-life of I31F, S360A, and T263L did not increase much compared to that of WT.

The thermodynamic stability of a protein could be evaluated by its melting temperature. The $T_{\mathrm{m}}$ values of the WT and variant enzymes were determined by nano-DSC. The $T_{\mathrm{m}}$ determinations showed that $\mathrm{T} 219 \mathrm{~L}$ and Mut 4 had a stabilizing effect on $\operatorname{LmSPase}$ (Fig. 2C). Both T219L $\left(58.0^{\circ} \mathrm{C}\right)$

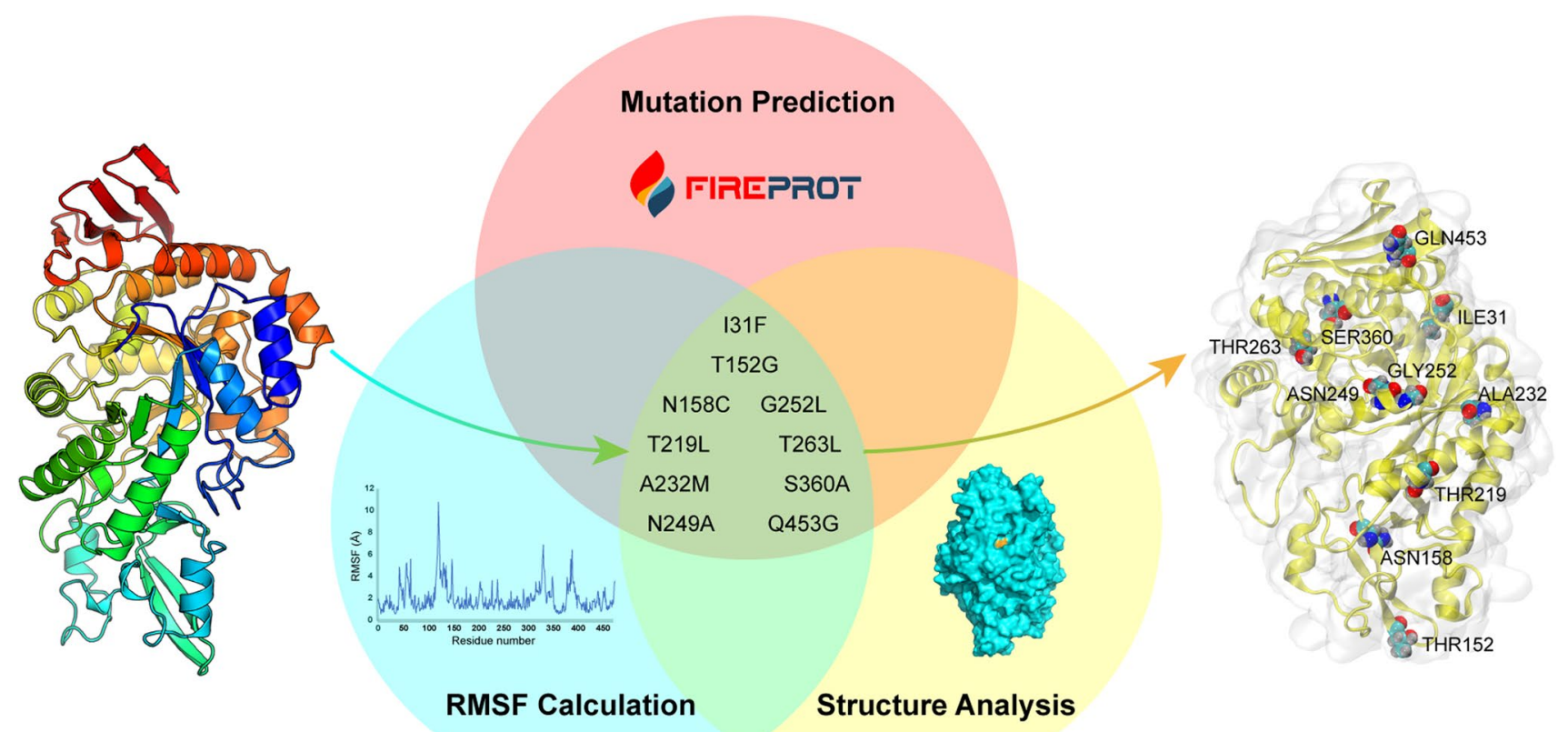

Fig. 1 Hotspot residues prediction. The mutations were predicted by FireProt server and selected based on RMSF calculation of MD simulations and structure analysis. The 3D structure model of LmSPase was shown in rainbow colors from dark blue (N-terminus) to red (C-terminus) (left). The ten hotspot residues of LmSPase are shown as spheres (right) 


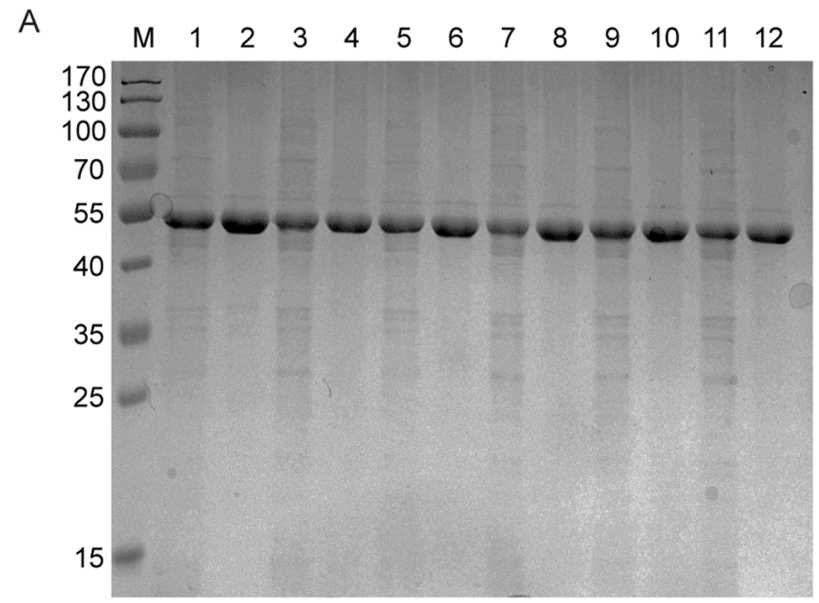

C

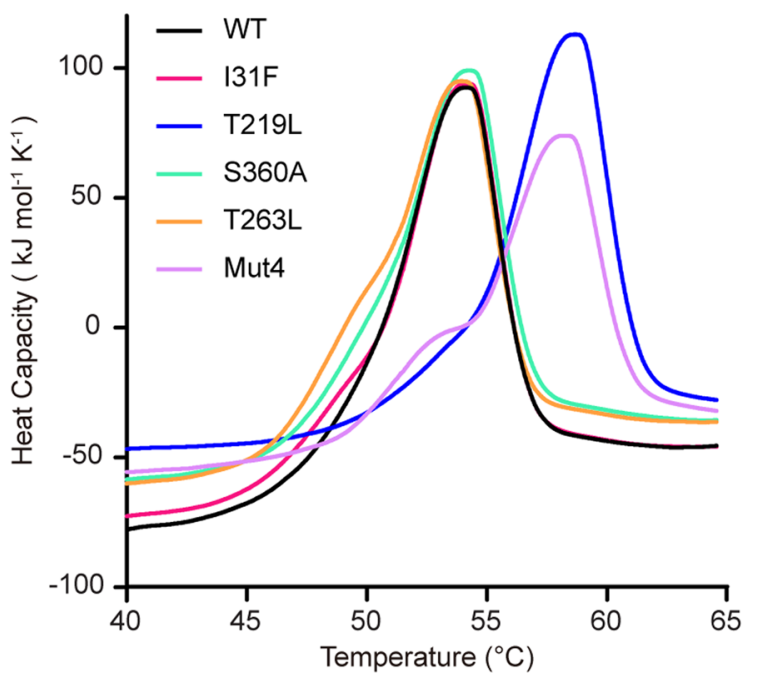

Fig. 2 Purification and characterizations of the wild-type LmSPase and variants. A The base lane is the cell lysate, and the even lane is the purified protein lanes: M, molecular weight marker; 1 and 2 , the wild type; 3 and 4, I31F; 5 and 6, T219L; 7 and 8, S360A; 9 and 10, T263L; 11 and 12 Mut4. B The half-life of the WT and variants determined at $50{ }^{\circ} \mathrm{C}$ in $50 \mathrm{mM}$ phosphate buffer, $\mathrm{pH} 6.5$ using

and Mut4 $\left(57.4{ }^{\circ} \mathrm{C}\right)$ had higher $T_{\mathrm{m}}$ values than that of WT $\left(53.4{ }^{\circ} \mathrm{C}\right)$, while the other mutations did not seem to affect the thermodynamic stability of LmSPase (Table 2). Far-UV CD spectra of the WT and variants showed that none of the mutations caused significant changes in the secondary structure (Fig. 2D).

\section{Catalytic production of aGG}

The $\alpha \mathrm{GG}$ is an efficient moisturizing agent and has been produced in the industry. The regular reaction temperature for producing $\alpha \mathrm{GG}$ is $30^{\circ} \mathrm{C}$. To investigate whether the two positive variants have advantages in the production of $\alpha \mathrm{GG}$ at a

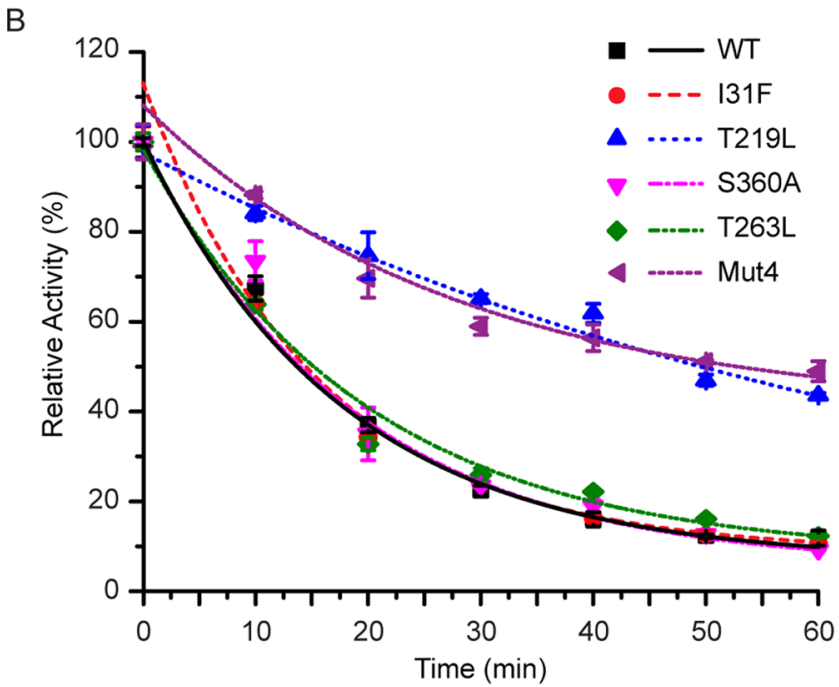

$\mathrm{D}$

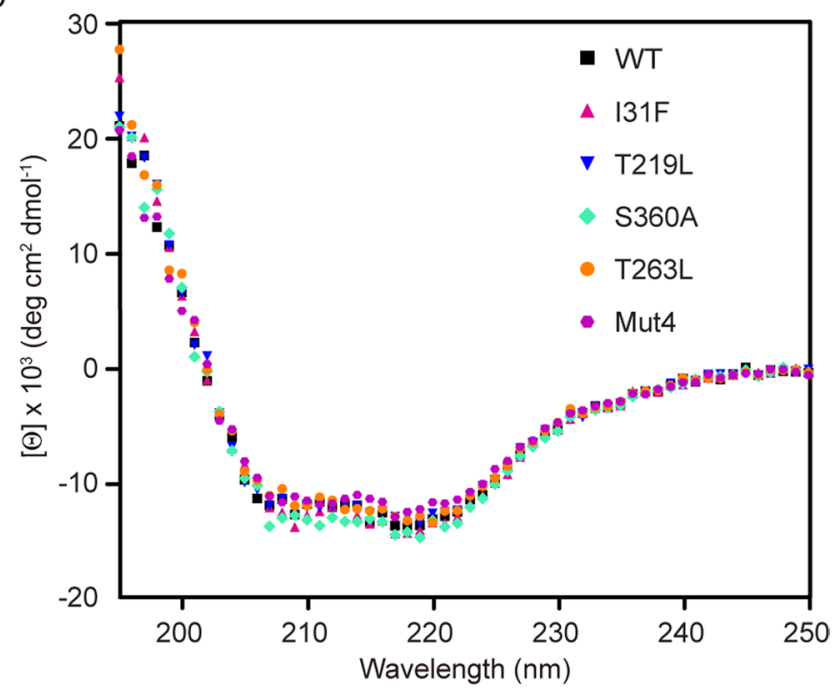

$0.01 \mathrm{mg} / \mathrm{mL}$ purified enzyme with the substrates sucrose and phosphates in the reaction mixture. The data points were fitted with exponential decay curves. C Calorimetric analysis. The $T_{\mathrm{m}}$ values of the $0.5 \mathrm{mg} / \mathrm{mL}$ purified WT and variants were determined by nano-DSC. D CD spectra analysis. The secondary structure of $0.2 \mathrm{mg} / \mathrm{mL}$ purified WT and variants were analyzed by CD

higher temperature, the crude extracts of T219L, Mut4, and WT were used to synthesize $\alpha \mathrm{GG}$ from $1.2 \mathrm{~mol} / \mathrm{L}$ sucrose and $2 \mathrm{~mol} / \mathrm{L}$ glycerol at $37{ }^{\circ} \mathrm{C}$ in MES buffer (Fig. 3A). After incubating with $40 \mathrm{U} / \mathrm{mL}$ crude extracts at $37^{\circ} \mathrm{C}$ for $60 \mathrm{~h}$, T219L and Mut4 achieved the product concentration of $193.2 \pm 12.9 \mathrm{~g} / \mathrm{L}$ and $195.8 \pm 13.1 \mathrm{~g} / \mathrm{L}$, which were approximately 1.3 -fold higher than that of WT $(150.4 \pm 10.0 \mathrm{~g} / \mathrm{L})$. During the first $24 \mathrm{~h}$ of the synthesis process, WT, T219L, and Mut 4 catalyzed the synthesis of $\alpha \mathrm{GG}$ quickly and tended to be flat at $36 \mathrm{~h}$. It can be found that the $\alpha \mathrm{GG}$ production of WT reached a high level at $36 \mathrm{~h}$, but there was no significant increase in the following $24 \mathrm{~h}$, while the two mutants still increased significantly from 36 to $60 \mathrm{~h}$, indicating that the 
Table 2 Characteristics of purified WT and variants

\begin{tabular}{llll}
\hline Enzyme & $\begin{array}{l}\text { Specific activity } \\
(\mathrm{U} / \mathrm{mg})\end{array}$ & $t_{1 / 2}(\mathrm{~min})$ & $T_{\mathrm{m}}\left({ }^{\circ} \mathrm{C}\right)$ \\
\hline Wild-type & $214.0 \pm 18.7$ & 14.6 & 53.4 \\
I31F & $220.3 \pm 16.9$ & 14.4 & 53.4 \\
T219L & $243.8 \pm 23.1$ & 48.7 & 58.0 \\
S360A & $230.2 \pm 20.4$ & 15.7 & 53.5 \\
T263L & $210.0 \pm 14.2$ & 15.1 & 53.0 \\
Mut4 & $198.7 \pm 18.8$ & 53.1 & 57.4 \\
\hline
\end{tabular}

${ }^{[\mathrm{a}]}$ The values of purified protein represent the means \pm S.D. for three independent experiments

The half-lives $\left(t_{1 / 2}\right)$ of enzymes were evaluated by incubating $0.01 \mathrm{mg} / \mathrm{mL}$ purified enzymes for $90 \mathrm{~min}$ in a water bath at $50{ }^{\circ} \mathrm{C}$ and testing their residual activity every $10 \mathrm{~min}$. The $T_{\mathrm{m}}$ values were determined by nano-DSC, and the $0.5 \mathrm{mg} / \mathrm{mL}$ of purified enzymes were scanned from 20 to $100{ }^{\circ} \mathrm{C}$ by the scan rate at $1^{\circ} \mathrm{C} / \mathrm{min}$

mutants with higher thermostability had advantages in the long-term catalysis process. Correspondingly, the molar conversion ratio of sucrose gradually increased with the extension of the catalytic time (Fig. 3B). After $36 \mathrm{~h}$, the sucrose conversion ratio of WT slowed down, while the two mutants continued to increase. Finally, the sucrose molar conversion ratio of T219L and Mut4 reached $63.3 \%$ and $64.2 \%$, respectively, which increased by approximately $28 \%$ compared to that of WT. As the Mut4 variant (I31F/T219L/T263L/ S360A) which was constructed based on the T219L mutant showed no significant improvement on catalytic performance compared with T219L, further computational analysis was carried out to get the insight of the reason for thermostability enhancement of the T219L variant.

\section{RMSD analysis of thermostable variants}

In this study, MD simulations were used to analyze the structural properties of the SPase enzyme. The root-mean-square deviation (RMSD) of the enzyme backbone atoms can reflect the whole protein stability during MD simulations. The stability of WT and its mutants was analyzed by MD simulations at $300 \mathrm{~K}$ and $335 \mathrm{~K}$. The RMSD of the WT at $300 \mathrm{~K}$ is between 2 and $2.5 \AA$, which is the typical value for globular proteins. After heating to $335 \mathrm{~K}$, it can be observed that the average RMSD of the WT is distributed between 2.5 and $3.5 \AA$, which is higher than that at $300 \mathrm{~K}$ (Fig. 4). Similarly, both T219L and Mut4 have lower RMSD values at $300 \mathrm{~K}$ than at $335 \mathrm{~K}$. Either at $300 \mathrm{~K}$ or at $335 \mathrm{~K}$, the average RMSD values of T219L and Mut4 were lower than that of the WT, indicating that T219L and Mut4 had a more stable protein backbone.

\section{RMSF analysis of thermostable variants}

The root-mean-square fluctuations (RMSF) reflect the possibility of movements of each amino acid in the protein, and a larger RMSF value reflects that residue has more degrees of freedom than those with smaller ones. Analysis of the RMSF plots generated based on MD simulations at $300 \mathrm{~K}$ and $350 \mathrm{~K}$ (Fig. 5A and B) showed that most parts of all variants of a protein are similar. Large changes between the WT and other variants can be observed for residues 122-125 and 455-457. Residues 128-133, 307-327, 337-357, and 382-399 had higher RMSF values of WT than those of T219L and Mut4. These regions with high RMSF values may affect the stability of SPase.

\section{Residues' contact analysis of thermostable variants}

Analysis of residue contacts of thermostable proteins in comparison to mesophilic proteins often shows changes in small polar amino acids to hydrophobic ones, and the increasing hydrophobicity of amino acids is one of the crucial factors in enhancing the thermostability of proteins primarily by enlarging the hydrophobic cores inside a protein,

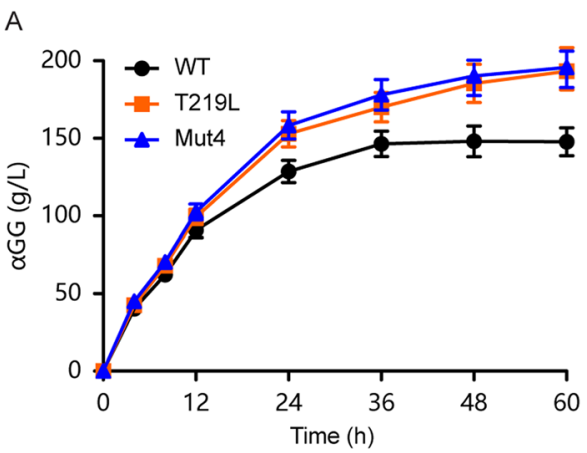

Fig. 3 Catalytic production of $\alpha$ GG. A The $\alpha$ GG synthesis. The recombinant $L m S P a s e s$ were used to catalyze sucrose and glycerol to produce $\alpha \mathrm{GG}$ at $37^{\circ} \mathrm{C}$. The reaction mixture containing $1.2 \mathrm{~mol} / \mathrm{L}$

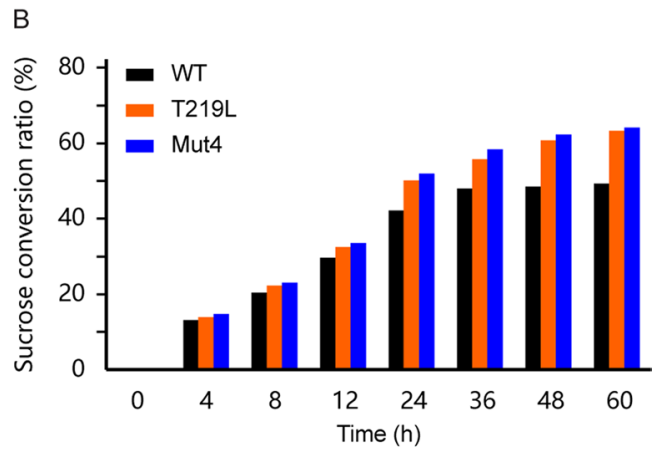

sucrose, $2 \mathrm{~mol} / \mathrm{L}$ glycerol, and $40 \mathrm{U} / \mathrm{mL}$ crude extracts of $L m$ SPase. B The molar conversion ratio of sucrose. The consumption of sucrose in reaction mixture was determined by HPLC 


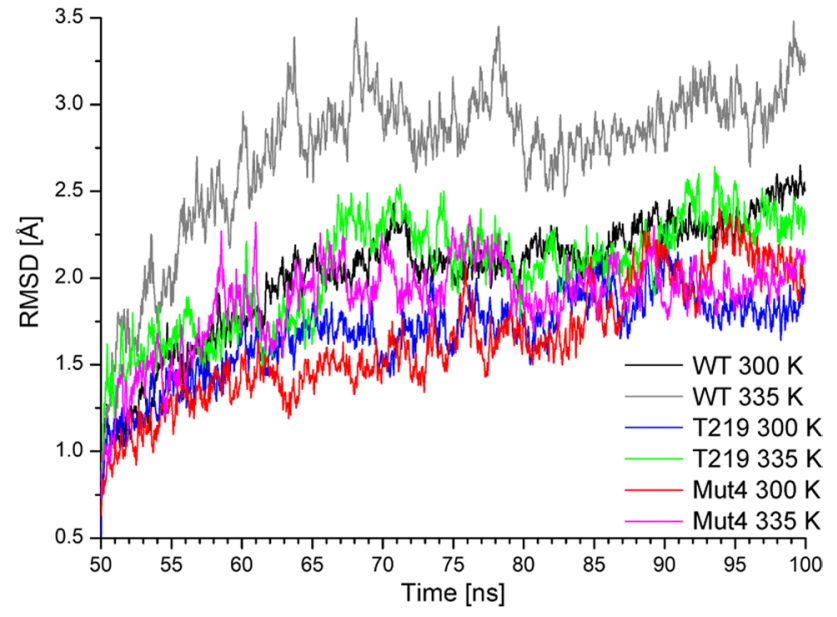

Fig. 4 The RMSD of the WT, T219L, and Mut4. The MD simulations were performed at $300 \mathrm{~K}$ and $335 \mathrm{~K}$ for $50-100 \mathrm{~ns}$. WT $300 \mathrm{~K}$ (black), WT $335 \mathrm{~K}$ (gray), T219L $300 \mathrm{~K}$ (blue), T219L $335 \mathrm{~K}$ (green), Mut $4300 \mathrm{~K}$ (red), Mut $4335 \mathrm{~K}$ (magenta). The MD simulations were calculated using NAMD 2.12 code, and the results were analyzed by VMD

thus removing water molecules from proteins' interior (Hait et al. 2020; Haney et al. 1999). Contact was defined as a distance lower than $5 \AA$ between two atoms from two different amino acids. In Figure S3, contacts from three simulations at $300 \mathrm{~K}$ are shown for the four mutated amino acids. For the case of the T219L mutant, large changes in interactions can be observed. All residues with improved contacts with L219 are close to the active site (D196 and E237), stabilizing it by creating a hydrophobic core often present in thermophilic proteins (Hait et al. 2020), which is difficult to destroy with

A

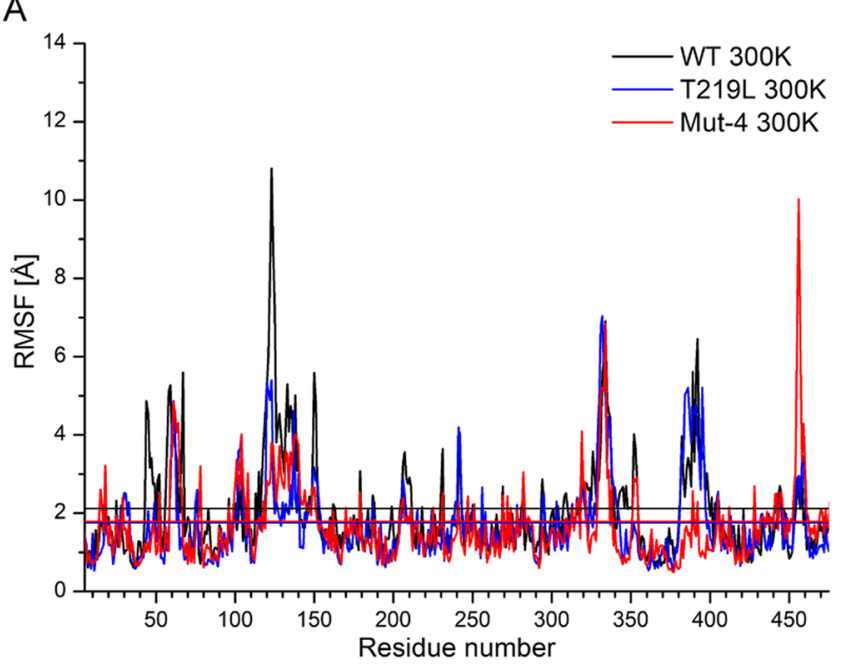

high temperature. In the Mut4 variant, amino acid on the position 219 has the same contacts as in a single mutation, but other residues (I31F, T263L, S360A) do not show significant changes in contacts. Thus Mut 4 does not exhibit improved thermostability in comparison to the T219L variant (Figure S3).

\section{Discussion}

SPase has a wide range of receptor specificity as it can transfer the glucose group in sucrose to different receptors. The glycosylated product has superior performance and can be used in food, pharmaceuticals, cosmetics, and other industrial fields. However, the deficient thermostability limits enzyme's application in continuous industrial production (Xu et al. 2020). Take the production of $\alpha \mathrm{GG}$ as an example. In most cases, $\mathrm{LmSPase}$ was used to catalyze the synthesis of $\alpha \mathrm{GG}$ under $30^{\circ} \mathrm{C}$ (Bolivar et al. 2017; Goedl et al. 2008), and maintaining low reaction temperature by refrigeration usually causes enormous redundant energy cost. Therefore, it's necessary to improve the thermostability of $L m S P$ ase, as the $\alpha \mathrm{GG}$ synthesis process usually takes several days, and enzymes are easy to gradually inactivate during such long time. Recently, improving the thermostability of SPases to enhance their usability in the industry has attracted increasing interest. For instance, Cerdobbel increased the thermostability of SPase from Bifidobacterium adolescentis by a combination of sequence- and structure-based mutagenesis (Cerdobbel et al. 2011). Bolivar improved the stability of SPase from L. mesenteroides by immobilization (Bolivar et al. 2017).

In this study, we applied a semi-rational design strategy combining computational prediction tools, structure-function

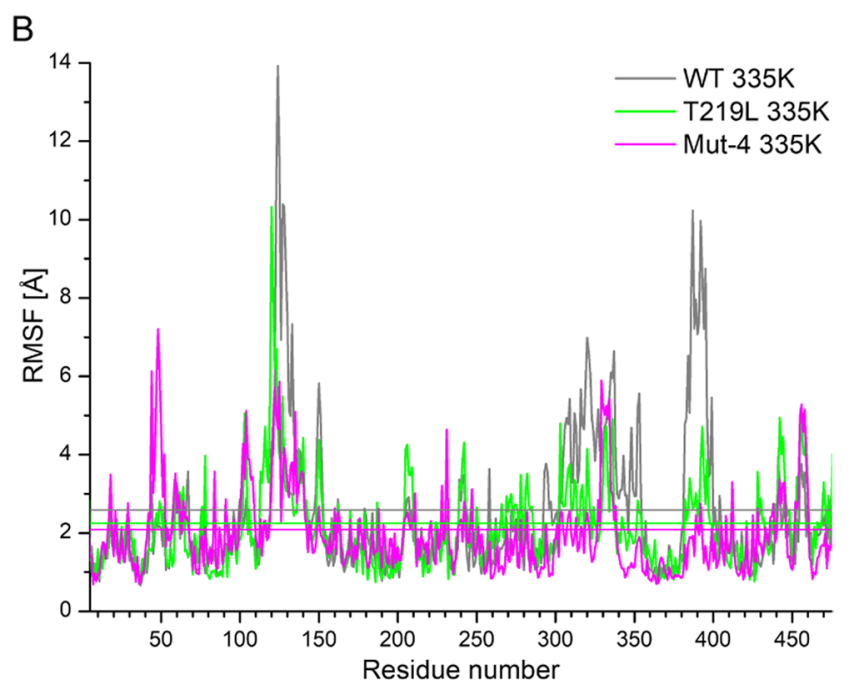

Fig. 5 The RMSF and structure analysis. The MD simulations of WT, T219L, and Mut4 were separately performed at $300 \mathrm{~K}$ (A) and $335 \mathrm{~K}$ (B) (scales are the same). Straight horizontal lines are mean values of RMSF plots 
analysis, and MD simulations to reduce screening scale and increased the possibility of obtaining positive mutations. The positive variant T219L with higher thermostability and activity was obtained. Although the combination mutant Mut4 also showed similarly improved performance, the analysis results showed that the critical factor is the residue 219. Additionally, the T219L variant showed advantages in the process of synthesizing $\alpha \mathrm{GG}$ from sucrose and glycerol at $37^{\circ} \mathrm{C}$. At $60 \mathrm{~h}$, the concentration of $\alpha \mathrm{GG}$ synthesized by such mutant reached more than $190 \mathrm{~g} / \mathrm{L}$ (production intensity was $3.2 \mathrm{~g} / \mathrm{L} / \mathrm{h}$ ) and still gradually increased after further incubation (Fig. 3). The most recent high $\alpha \mathrm{GG}$ concentration can be achieved through various protein engineering methods or immobilization of SPase (Bolivar et al. 2017). Our results provide an alternative for improving the product concentration of $\alpha \mathrm{GG}$ at high temperatures compared with traditional enzyme immobilization technology.

To study the thermostability enhancement factors, MD simulations were performed. The RMSD results showed that the variant had more stable protein backbones (Fig. 4), which were in good agreement with the experimental results (Fig. 2C). The RMSF results showed that the variant had fewer flexible regions (Fig. 5), and the amino acids in these regions of WT were located on a long loop exposed to the solvent, which would cause a relatively high fluctuation. Tailoring such flexible regions might have a positive effect on the catalytic performance of SPase under harsh conditions. Similar behavior of RMSD and RMSF in the analysis of thermostable proteins is observed in studies for other enzymes like lipase (Wang et al. 2020), trehalose synthase (Chen et al. 2021), or methylenetetrahydrofolate dehydrogenase (Maiello et al. 2020). Furthermore, the intermolecular interactions between the residues were analyzed. The mutated residue of the positive variant had more interactions with the surrounding residues than that of WT, which might contribute to the enhanced thermostability of the variant. Such creation of hydrophobic cores was observed during analysis of mesophilic and thermophilic proteins sequences (Haney et al. 1999; Saelensminde et al. 2009). During the process of MD simulations, when residue is mutated into hydrophobic amino acid, the hydrophobic core can be formed, such as in neurotensin receptor (Lee et al. 2015), enzymes like trehalose synthase (Chen et al. 2021), and nitrile hydratase (Cheng et al. 2020; Guo et al. 2021). The semi-rational design approach established in the present study sheds light on the future engineering of other industrial attractive SPases, such as the one from Bifidobacterium adolescentis.

Supplementary Information The online version contains supplementary material available at https://doi.org/10.1007/s00253-021-11551-0.

Author contribution $\mathrm{YX}$ designed the project and purified the proteins. YX and LP wrote the manuscript; XL constructed the plasmids and characterize the proteins; LY synthesized the $\alpha \mathrm{GG}$ and tested relative statistics; $\mathrm{XL}, \mathrm{WS}, \mathrm{XC}$, and YC helped analyzed data and revised the manuscript.
LP designed theoretical investigations, created homology models, ran the MD simulations, and analyzed the data. All the authors read and approved the final manuscript.

Funding This study was funded by the National Natural Science Foundation of China (32001064), the China Postdoctoral Science Foundation (2020M671331), the Natural Science Foundation of Jiangsu province (BK20171138), the 111 Project (No.1112-06), and the Program of the Key Laboratory of Industrial Biotechnology, Ministry of Education (KLIB-KF202008).

The computational results used in this article were obtained using Interdisciplinary Center for Modern Technologies facilities, NCU, Torun, Poland.

Data availability All data generated or analyzed during this study are included in this published article (and its supplementary information files).

\section{Declarations}

Ethical approval This article does not contain any studies with human participants or animals by any of the authors.

Consent to participate Not applicable.

Consent for publication All authors have read and approved the manuscript for submission and publication.

Conflict of interest The authors declare no competing interests.

Open Access This article is licensed under a Creative Commons Attribution 4.0 International License, which permits use, sharing, adaptation, distribution and reproduction in any medium or format, as long as you give appropriate credit to the original author(s) and the source, provide a link to the Creative Commons licence, and indicate if changes were made. The images or other third party material in this article are included in the article's Creative Commons licence, unless indicated otherwise in a credit line to the material. If material is not included in the article's Creative Commons licence and your intended use is not permitted by statutory regulation or exceeds the permitted use, you will need to obtain permission directly from the copyright holder. To view a copy of this licence, visit http://creativecommons.org/licenses/by/4.0/.

\section{References}

Alford RF, Leaver-Fay A, Jeliazkov JR, O’Meara MJ, DiMaio FP, Park H, Shapovalov MV, Renfrew PD, Mulligan VK, Kappel K, Labonte JW, Pacella MS, Bonneau R, Bradley P, Dunbrack RL Jr, Das R, Baker D, Kuhlman B, Kortemme T, Gray JJ (2017) The Rosetta Allatom energy function for macromolecular modeling and design. $\mathrm{J}$ Chem Theory Comput 13:3031-3048. https://doi.org/10.1021/acs. jctc. $7 \mathrm{~b} 00125$

Bednar D, Beerens K, Sebestova E, Bendl J, Khare S, Chaloupkova R, Prokop Z, Brezovsky J, Baker D, Damborsky J (2015) FireProt: energy- and evolution-based computational design of thermostable multiple-point mutants. PLoS Comput Biol 11:e1004556. https://doi. org/10.1371/journal.pcbi.1004556

Bolivar JM, Luley-Goedl C, Leitner E, Sawangwan T, Nidetzky B (2017) Production of glucosyl glycerol by immobilized sucrose phosphorylase: options for enzyme fixation on a solid support and application in microscale flow format. J Biotechnol 257:131-138. https://doi.org/10.1016/j.jbiotec.2017.01.019 
Cerdobbel A, De Winter K, Aerts D, Kuipers R, Joosten H-J, Soetaert W, Desmet T (2011) Increasing the thermostability of sucrose phosphorylase by a combination of sequence- and structure-based mutagenesis. Protein Eng Des Sel 24:829-834. https://doi.org/10. 1093/protein/gzr042

Chen Y, Zhao Y, Zhou X, Liu N, Ming D, Zhu L, Jiang L (2021) Improving the thermostability of trehalose synthase from Thermomonospora curvata by covalent cyclization using peptide tags and investigation of the underlying molecular mechanism. Int J Biol Macromol 168:13-21. https://doi.org/10.1016/j.ijbiomac.2020.11.195

Cheng Z, Lan Y, Guo J, Ma D, Jiang S, Lai Q, Zhou Z, Peplowski L (2020) Computational design of nitrile hydratase from Pseudonocardia thermophila JCM3095 for improved thermostability. Molecules 25:4806. https://doi.org/10.3390/molecules25204806

Chica RA, Doucet N, Pelletier JN (2005) Semi-rational approaches to engineering enzyme activity: combining the benefits of directed evolution and rational design. Curr Opin Biotechnol 16:378-384. https://doi. org/10.1016/j.copbio.2005.06.004

Dolinsky TJ, Czodrowski P, Li H, Nielsen JE, Jensen JH, Klebe G, Baker NA (2007) PDB2PQR: expanding and upgrading automated preparation of biomolecular structures for molecular simulations. Nucleic Acids Res 35:W522-525. https://doi.org/10.1093/nar/gkm276

Dolinsky TJ, Nielsen JE, McCammon JA, Baker NA (2004) PDB2PQR: an automated pipeline for the setup of Poisson-Boltzmann electrostatics calculations. Nucleic Acids Res 32:W665-667. https://doi.org/10. 1093/nar/gkh381

Eisenberg D, Lüthy R, Bowie JU (1997) VERIFY3D: assessment of protein models with three-dimensional profiles. Methods Enzymol 277:396-404. https://doi.org/10.1016/s0076-6879(97)77022-8

Franceus J, Capra N, Desmet T, Thunnissen AWH (2019) Structural comparison of a promiscuous and a highly specific sucrose $6(\mathrm{~F})$ phosphate phosphorylase. Int J Mol Sci 20:3906. https://doi.org/10. 3390/ijms20163906

Franceus J, Desmet T (2020) Sucrose phosphorylase and related enzymes in glycoside hydrolase family 13: discovery, application and engineering. Int J Mol Sci 21:2526. https://doi.org/10.3390/ijms21072526

Goedl C, Sawangwan T, Mueller M, Schwarz A, Nidetzky B (2008) A high-yielding biocatalytic process for the production of 2-O-(alphaD-glucopyranosyl)-sn-glycerol, a natural osmolyte and useful moisturizing ingredient. Angew Chem Int Ed Engl 47:10086-10089. https://doi.org/10.1002/anie.200803562

Goedl C, Sawangwan T, Wildberger P, Nidetzky B (2010) Sucrose phosphorylase: a powerful transglucosylation catalyst for synthesis of $\alpha$-D-glucosides as industrial fine chemicals. Biocatal Biotransform 28:10-21. https://doi.org/10.3109/10242420903411595

Guex N, Peitsch MC, Schwede T (2009) Automated comparative protein structure modeling with SWISS-MODEL and Swiss-PdbViewer: a historical perspective. Electrophoresis 30(Suppl 1):S162-173. https:// doi.org/10.1002/elps.200900140

Guo J, Cheng Z, Berdychowska J, Zhu X, Wang L, Peplowski L, Zhou Z (2021) Effect and mechanism analysis of different linkers on efficient catalysis of subunit-fused nitrile hydratase. Int J Biol Macromol 181:444-451. https://doi.org/10.1016/j.ijbiomac.2021.03.103

Hait S, Mallik S, Basu S, Kundu S (2020) Finding the generalized molecular principles of protein thermal stability. Proteins 88:788-808. https://doi.org/10.1002/prot.25866

Haki GD, Rakshit SK (2003) Developments in industrially important thermostable enzymes: a review. Bioresour Technol 89:17-34. https://doi. org/10.1016/s0960-8524(03)00033-6

Haney PJ, Badger JH, Buldak GL, Reich CI, Woese CR, Olsen GJ (1999) Thermal adaptation analyzed by comparison of protein sequences from mesophilic and extremely thermophilic Methanococcus species. Proc Natl Acad Sci U S A 96:3578-3583. https://doi.org/10. 1073/pnas.96.7.3578
Humphrey W, Dalke A, Schulten K (1996) VMD: visual molecular dynamics. J Mol Graph 14:33-38. https://doi.org/10.1016/02637855(96)00018-5

Lee S, Bhattacharya S, Tate CG, Grisshammer R, Vaidehi N (2015) Structural dynamics and thermostabilization of neurotensin receptor 1 . $\mathrm{J}$ Phys Chem B 119(15):4917-4928. https://doi.org/10.1021/jp510735f

Luthy R, Bowie JU, Eisenberg D (1992) Assessment of protein models with three-dimensional profiles. Nature 356:83-85. https://doi.org/ $10.1038 / 356083 \mathrm{a} 0$

Mackerell AD, Feig M, Brooks CL (2004) Extending the treatment of backbone energetics in protein force fields: limitations of gas-phase quantum mechanics in reproducing protein conformational distributions in molecular dynamics simulations. J Comput Chem 25:1400 1415. https://doi.org/10.1002/jcc.20065

MacKerell AD Jr, Bashford D, Bellott M, Dunbrack RL Jr, Evanseck JD, Field MJ, Fischer S, Gao J, Guo H, Ha S, Joseph-McCarthy D, Kuchnir L, Kuczera K, Lau FTK, Mattos C, Michnick S, Ngo T, Nguyen DT, Prodhom B, Reiher WE III, Roux B, Schlenkrich M, Smith JC, Stote R, Straub J, Watanabe M, Wiorkiewicz-Kuczera J, Yin D, Karplus M (1998) All-atom empirical potential for molecular modeling and dynamics studies of proteins. J Phys Chem B 102:3586-3616. https://doi.org/10.1021/jp973084f

Maiello F, Gallo G, Coelho C, Sucharski F, Hardy L, Würtele M (2020) Crystal structure of Thermus thermophilus methylenetetrahydrofolate dehydrogenase and determinants of thermostability. PloS One 15(5):e0232959. https://doi.org/10.1371/journal.pone.0232959

Musil M, Stourac J, Bendl J, Brezovsky J, Prokop Z, Zendulka J, Martinek T, Bednar D, Damborsky J (2017) FireProt: web server for automated design of thermostable proteins. Nucleic Acids Res 45:W393-399. https://doi.org/10.1093/nar/gkx285

O’Neill EC, Field RA (2015) Enzymatic synthesis using glycoside phosphorylases. Carbohydr Res 403:23-37. https://doi.org/10.1016/j. carres.2014.06.010

Olsson MH, Søndergaard CR, Rostkowski M, Jensen JH (2011) PROPKA3: consistent treatment of internal and surface residues in empirical pKa predictions. J Chem Theory Comput 7:525-537. https://doi.org/10.1021/ct100578z

Phillips JC, Braun R, Wang W, Gumbart J, Tajkhorshid E, Villa E, Chipot C, Skeel RD, Kale L, Schulten K (2005) Scalable molecular dynamics with NAMD. J Comput Chem 26:1781-1802. https://doi.org/10. $1002 /$ jcc. 20289

Phillips JC, Hardy DJ, Maia JDC, Stone JE, Ribeiro JV, Bernardi RC, Buch R, Fiorin G, Hénin J, Jiang W, McGreevy R, Melo MCR, Radak BK, Skeel RD, Singharoy A, Wang Y, Roux B, Aksimentiev A, LutheySchulten Z, Kalé LV, Schulten K, Chipot C, Tajkhorshid E (2020) Scalable molecular dynamics on CPU and GPU architectures with NAMD. J Chem Phys 153:044130. https://doi.org/10.1063/5.00144 75

Roth T, Beer B, Pick A, Sieber V (2017) Thermostabilization of the uronate dehydrogenase from Agrobacterium tumefaciens by semirational design. AMB Express 7:1-9. https://doi.org/10.1186/ s13568-017-0405-2

Roy A, Kucukural A, Zhang Y (2010) I-TASSER: a unified platform for automated protein structure and function prediction. Nat Protoc 5:725-738. https://doi.org/10.1038/nprot.2010.5

Saelensminde G, Halskau Ø, Jonassen I (2009) Amino acid contacts in proteins adapted to different temperatures: hydrophobic interactions and surface charges play a key role. Extremophiles 13(1):1120. https://doi.org/10.1007/s00792-008-0192-4

Schymkowitz J, Borg J, Stricher F, Nys R, Rousseau F, Serrano L (2005) The FoldX web server: an online force field. Nucleic Acids Res 33:W382-388. https://doi.org/10.1093/nar/gki387

Sun Z, Liu Q, Qu G, Feng Y, Reetz MT (2019) Utility of b-factors in protein science: interpreting rigidity, flexibility, and internal motion and engineering thermostability. Chem Rev 119:16261665. https://doi.org/10.1021/acs.chemrev.8b00290 
Wang R, Wang S, Xu Y, Yu X (2020) Enhancing the thermostability of Rhizopus chinensis lipase by rational design and MD simulations. Int J Biol Macromol 160:1189-1200. https://doi.org/10.1016/j. ijbiomac.2020.05.243

Waterhouse A, Bertoni M, Bienert S, Studer G, Tauriello G, Gumienny R, Heer FT, de Beer TAP, Rempfer C, Bordoli L, Lepore R, Schwede T (2018) SWISS-MODEL: homology modelling of protein structures and complexes. Nucleic Acids Res 46:W296303. https://doi.org/10.1093/nar/gky427

Xu Z, Cen Y-K, Zou S-P, Xue Y-P, Zheng Y-G (2020) Recent advances in the improvement of enzyme thermostability by structure modification. Crit Rev Biotechnol 40:83-98. https://doi.org/10.1080/ 07388551.2019 .1682963

Yang J, Yan R, Roy A, Xu D, Poisson J, Zhang Y (2015) The I-TASSER Suite: protein structure and function prediction. Nat Methods 12:7-8. https://doi.org/10.1038/nmeth.3213
Yao D, Fan J, Han R, Xiao J, Li Q, Xu G, Dong J, Ni Y (2020) Enhancing soluble expression of sucrose phosphorylase in Escherichia coli by molecular chaperones. Protein Expression Purif 169:105571. https://doi.org/10.1016/j.pep.2020.105571

Zhang Y (2008) I-TASSER server for protein 3D structure prediction. BMC Bioinf 9:40. https://doi.org/10.1186/1471-2105-9-40

Publisher's note Springer Nature remains neutral with regard to jurisdictional claims in published maps and institutional affiliations. 